\title{
Is There A Role for Limited Parotid Resections for Primary Malignant Parotid Tumors?
}

Miquel Quer ${ }^{1,2,3, *} \mathbb{0}$, Kerry D. Olsen ${ }^{4}$, Carl E. Silver ${ }^{5}$, Marc Hamoir ${ }^{6}{ }^{\circ}$, Antti A. Mäkitie ${ }^{7,8,9}$, Juan P. Rodrigo ${ }^{10,11}{ }^{\mathbb{D}}$, Vincent Vander Poorten ${ }^{3,12}$, Robert P. Takes ${ }^{13}$, Henrik Hellquist ${ }^{14}$, Jacinto García Lorenzo ${ }^{1,2}$, Orlando Guntinas-Lichius ${ }^{3,15,16} \mathbb{D}^{\mathbb{D}}$, Remco de Bree ${ }^{17}$ (D), Carlos Suárez ${ }^{18}$, Luiz P. Kowalski ${ }^{19}$, José G. Vartanian ${ }^{19}$ (D) Alvaro Sanabria $20{ }^{D}$, Ashok R. Shaha ${ }^{21}$, Peter Zbären ${ }^{22}$, Alessandra Rinaldo 23 and Alfio Ferlito $24(\mathbb{D}$

1 Department of Otolaryngology-Head and Neck Surgery, University Hospital de la Santa Creu i Sant Pau, 08041 Barcelona, Spain; jgarcial@santpau.cat

2 Department of Surgery, Universitat Autonòma de Barcelona, 08193 Bellaterra, Barcelona, Spain

3 Multidisciplinary Salivary Gland Society, 1204 Genève, Switzerland; vincent.vanderpoorten@uzleuven.be 4 Department of Otorhinolaryngology, Mayo Clinic, Rochester, MN 55902, USA; olsen.kerry@mayo.edu

5 Department of Surgery, University of Arizona College of Medicine, Phoenix, AZ 85724, USA; csilver@cox.net

6 Department of Head and Neck Surgery, Head and Neck Oncology Program, St Luc University Hospital and King Albert II Cancer Institute, 1200 Brussels, Belgium; Marc.Hamoir@uclouvain.be

7 Department of Otorhinolaryngology-Head and Neck Surgery, Helsinki University Hospital and University of Helsinki, 00029 Helsinki, Finland; Antti.Makitie@hus.fi

8 Research Program in Systems Oncology, Faculty of Medicine, University of Helsinki, 00100 Helsinki, Finland

9 Department of Clinical Sciences Intervention and Technology, Division of Ear, Nose and Throat Diseases, Karolinska University Hospital, Stockholm, 17164 Solna, Sweden

10 Department of Otolaryngology, Hospital Universitario Central de Asturias, 33011 Oviedo, Asturias, Spain; jprodrigo@uniovi.es

11 Instituto Universitario de Oncología del Principado de Asturias (IUOPA), University of Oviedo, 33006 Oviedo, Asturias, Spain

12 Otorhinolaryngology-Head and Neck Surgery and Department of Oncology, Section Head and Neck Oncology, University Hospitals Leuven, KU Leuven, 3000 Leuven, Belgium

13 Department of Otolaryngology-Head and Neck Surgery, Radboud University Medical Center, 6525 GA Nijmegen, The Netherlands; Robert.Takes@radboudumc.nl

14 Department of Biomedical Sciences and Medicine, University of Algarve, 8005-139 Faro, Portugal; henrikhellquist@gmail.com

15 Department of Otorhinolaryngology, Institute of Phoniatry/Audiology, Jena University Hospital, 07743 Jena, Germany; orlando.guntinas@med.uni-jena.de

16 Facial Nerve Center, Jena University Hospital, 07743 Jena, Germany

17 Department of Head and Neck Surgical Oncology, University Medical Center Utrecht, 3584 CX Utrecht, The Netherlands; R.deBree@umcutrecht.nl

18 Instituto de Investigación Sanitaria del Principado de Asturias, 33011 Oviedo, Asturias, Spain; csuareznieto@gmail.com

19 Department Otorhinolaryngology-Head and Neck Surgery, Centro de Tratamento e Pesquisa Hospital do Cancer A.C. Camargo, 01508-010 São Paulo, Brazil; lp_kowalski@uol.com.br (L.P.K.); jgvartanian@uol.com.br (J.G.V.)

20 Department of Surgery, School of Medicine, Universidad de Antioquia- Hospital Universitario San Vicente Fundacion, CEXCA Centro de Excelencia en Enfermedades de Cabeza y Cuello, Medellin 1226, Colombia; alvarosanabria@gmail.com

21 Memorial Sloan Kettering Cancer Center, New York, NY 10065, USA; shahaa@MSKCC.ORG

22 Department of Otorhinolaryngology-Head and Neck Surgery, Inselspital, Universitätsspital Bern, 3010 Bern, Switzerland; p.zbaeren@hotmail.fr

23 University of Udine School of Medicine, 33100 Udine UD, Italy; alessandra.rinaldo@uniud.it

24 International Head and Neck Scientific Group, 35100 Padua, Italy; alfio.ferlito@uniud.it

* Correspondence: mquer@santpau.cat 
Abstract: (1) Background: Lateral or total parotidectomy are the standard surgical treatments for malignant parotid tumors. However, some authors have proposed a more limited procedure. (2) Methods: We performed a review of the literature on this topic. Studies were included that met the following criteria: malignant parotid tumors, information about the extent of surgical resection, treated with less than a complete lateral lobectomy, and information on local control and/or survival. Nine articles fulfilled the inclusion criteria. (3) Results: Eight of the nine series reported favorable results for the more limited approaches. Most used them for small, mobile, low-grade cancers in the lateral parotid lobe. Most authors have used a limited partial lateral lobectomy for a presumed benign lesion. The remaining study analyzed pediatric patients treated with enucleation with poor local control. (4) Conclusions: There is weak evidence for recommending less extensive procedures than a lateral parotid lobectomy. In the unique case of a partial lateral parotidectomy performed for a tumor initially thought to be benign but pathologically proved to be malignant, close follow-up can be recommended for low grade $\mathrm{T} 1$ that has been excised with free margins and does not have adverse prognostic factors.

Keywords: primary malignant parotid tumors; parotid malignancy; parotid tumors; partial parotid surgery; parotid surgery

\section{Introduction}

Surgery is considered the primary treatment modality for most malignant parotid tumors. The extent of the surgery depends mainly on the local extent of the disease [1-10]. In advanced tumors (T3 and T4), there is consensus that a total parotidectomy is the standard local treatment. In contrast, for early tumors (T1, N0), the extent of resection is still controversial. The standard approach has been total parotidectomy or lateral parotid lobectomy. One debated issue is whether to extirpate the deep lobe of the gland to remove the intraparotid deep lobe nodes [1-10]. This is done when there is evidence of superficial parotid or neck node metastasis from a parotid gland cancer, or if the tumor is of high-grade histology. Controversy regarding the extent of the gland to be removed also occurs as some recommend [11] a more limited resection than complete lateral lobectomy. Limited parotid surgery is becoming more frequent in the management of benign tumors, and as a result, more malignant tumors are incidentally found after partial surgery. When limited parotid surgery is done for a presumably benign tumor, and final histology reveals malignancy, subsequent treatment is often dictated by the final pathologic findings. For most cancers, the standard advice is to complete a total parotidectomy [1-8]. Recently, some advocate "watchful waiting", for small, low-grade, and free-margin resections [12].

The objective of this article is to review the literature regarding the use of partial parotid surgery for the treatment of malignant parotid tumors and try to define the proper indications for such procedures.

\section{Materials and Methods}

To analyze the role of limited resections for malignant primary parotid tumors, we conducted a systematic review of the current literature. A PubMed internet search was performed for English language publications between the years 1990 and 2019, using the following search criteria in the title or abstract: "parotid gland malignant tumor" or "parotid gland cancer" or "parotid surgery".

The search results were reviewed for potential eligible studies. When any abstract addressed procedures less extensive than lateral parotid lobectomy, the full article was searched. References were cross-checked to ensure inclusion of all relevant publications. Studies were selected if they met the following inclusion criteria: (1) patients treated for malignant parotid tumors, (2) information about the extent of surgical resection, (3) patients treated with less than lateral lobectomy, and (4) information on local control and/or survival.

Our search criteria identified 61 papers for data review and 9 articles fulfilled the inclusion criteria. 


\section{Results}

The nine articles (Table 1) are presented in the order of publication, but three articles of the same group are analyzed together.

Table 1. Publications in partial surgery for parotid malignant tumors.

\begin{tabular}{|c|c|c|c|c|}
\hline Year & Authors & $\begin{array}{c}\text { Number of Cases. } \\
\text { Complementary Treatment }\end{array}$ & $\begin{array}{l}\text { Histolo-Gical } \\
\text { Type }\end{array}$ & $\begin{array}{l}\text { Local Control (LC) } \\
\text { and Survival }\end{array}$ \\
\hline 1999 & Renehan et al. [13] & $\begin{array}{l}24 \text { extracapsular dissection (ECD) } \\
\text { (13 post-op radiotherapy) }\end{array}$ & $\begin{array}{l}\text { No specific } \\
\text { information }\end{array}$ & $\begin{array}{l}79 \% \text { LC ( } 5 \text { recurrences) } \\
68 \% 10 \text { years overall } \\
\text { survival. }\end{array}$ \\
\hline 1999 & Witt [14] & $\begin{array}{l}1 \text { PLL (low-grade, }<3 \mathrm{~cm} \text { ) } \\
\text { (No information on } \\
\text { complementary treatment) }\end{array}$ & $1 \mathrm{MEPCA}$ & $\begin{array}{c}100 \% \text { LC } \\
\text { No data on survival }\end{array}$ \\
\hline 2003 & McGurk et al. [15] & $\begin{array}{l}12 \text { ECD in selected cases (discrete, } \\
\text { mobile, and less than } 4 \mathrm{~cm} \\
\text { in diameter) } \\
\text { (7 post-op radiotherapy) }\end{array}$ & $\begin{array}{c}1 \text { ACC } \\
1 \text { AdCC } \\
7 \text { MEPCA } \\
3 \text { others (no } \\
\text { specified) }\end{array}$ & $\begin{array}{c}91.7 \% \text { LC ( } 1 \text { recurrence) } \\
\text { 100\% The 10-year } \\
\text { cancer-specific survival }\end{array}$ \\
\hline 2005 & Lim et al. [11] & $\begin{array}{l}43 \text { "conservative parotidectomy" } \\
\text { (less than superficial) } \\
\text { (10 post-op radiotherapy) }\end{array}$ & $\begin{array}{c}\text { Low-grade: } \\
11 \text { ACC } \\
9 \text { MEPCA } \\
6 \text { BCC } \\
1 \text { AdCC } \\
\text { High-grade: } \\
5 \text { MEPCA } \\
4 \text { AdCC } \\
3 \text { CEPA } \\
2 \text { ADC } \\
2 \text { SCC }\end{array}$ & $\begin{array}{l}90.5 \% \mathrm{LC}(4 \\
\text { recurrences) } \\
88 \% 5 \text { years overall } \\
\text { survival }\end{array}$ \\
\hline 2016 & Cockerill et al. [16] & $\begin{array}{c}11 \text { Enucleation } \\
\text { (No information on } \\
\text { complementary treatment) }\end{array}$ & $\begin{array}{l}\text { No specific } \\
\text { information }\end{array}$ & $36 \%$ LC (7 recurrences) \\
\hline 2017 & Stodulski et al. [17] & $\begin{array}{c}2 \text { PLL (II) low-intermediate grade, } \\
\text { (one T1 and one T2) with close } \\
\text { margins } \\
\text { (No post-op radiotherapy) }\end{array}$ & $\begin{array}{l}1 \mathrm{AdCC} \\
1 \mathrm{MEPCA}\end{array}$ & $\begin{array}{c}100 \% \text { LC } \\
100 \% \text { cancer-specific } \\
\text { survival }\end{array}$ \\
\hline 2019 & $\begin{array}{c}\text { Mantsopoulos et al. } \\
{[12,18,19]}\end{array}$ & $\begin{array}{c}14 \text { ECD low grade (13 T1 and one } \\
\text { T2). Free margins } \\
\text { (No post-op radiotherapy) }\end{array}$ & $\begin{array}{c}4 \text { ACC } \\
1 \text { BCC } \\
2 \text { CEPA } \\
7 \text { MEPCA }\end{array}$ & $\begin{array}{c}100 \% \text { LC } \\
100 \% \text { cancer-specific } \\
\text { survival }\end{array}$ \\
\hline TOTAL CASES & PLL & $\begin{array}{c}46 \text { cases } \\
\text { (10 post-op radiotherapy) }\end{array}$ & & $91 \%$ (4 recurrences) \\
\hline \multirow[t]{2}{*}{ TOTAL CASES } & ECD & 50 cases (20 post-op radiotherapy) & & $88 \%$ LC (6 recurrences) \\
\hline & Enucleation & $\begin{array}{c}11 \text { cases } \\
\text { (no information on radio) }\end{array}$ & & $36 \%$ LC (7 recurrences) \\
\hline
\end{tabular}

ACC, acinic cell carcinoma; ADC, adenocarcinoma; AdCC, adenoid cystic carcinoma; CEPA, carcinoma ex pleomorphic adenoma; BCC, basal cell adenocarcinoma; ED, extracapsular dissection; MEPCA, mucoepidermoid carcinoma; PLL, partial superficial parotidectomy; SCC, squamous cell carcinoma.

Renehan et al. [13] reported on 24 patients with a primary malignant parotid tumor treated by extracapsular dissection (ECD). Those tumors were classified as apparently benign, but definitive histology revealed malignancy. Of those 24 cases, 13 (54\%) received postoperative radiotherapy. The rate of local control was 79\% (5 recurrences), and the 10 -year overall survival was $68 \%$. The authors analyzed the subgroup (12 patients) with mobile tumors $<4 \mathrm{~cm}$ treated with extracapsular dissection. Of these, 50\% received post-operative radiotherapy. In this subgroup, the local control rate was $80 \%$ and the 10-year survival was 100\%. The authors stated than a conservative surgical approach for small, apparently "benign" parotid cancers did not compromise local control and survival rates.

Witt [14] published his experience with partial lateral lobe parotidectomy (PLL). Most of these PLL were done for benign tumors, but one patient had a low-grade mucoepidermoid carcinoma. It was a small $(<3 \mathrm{~cm})$ mobile tumor in the lateral lobe $(<3 \mathrm{~cm})$. The author reported good facial nerve function and no evidence of local recurrence. 
McGurk et al. [15] published their experience with 821 patients, where 5\% of benign tumors were subsequently shown to be malignant. The tumors were classified based on clinical criteria by the authors as simple (discrete, mobile, and less than $4 \mathrm{~cm}$ in diameter), and were treated with ECD. Definitive pathology revealed 12 patients with a malignant tumor treated by ECD, and of those, five did not have close or positive margins. The seven patients with a close or positive margin or with a high-grade tumor received postoperative radiotherapy. The outcome of those patients was good, with local recurrence in only one patient and a 10-year disease-specific survival of $100 \%$. The authors concluded that ECD is a viable alternative to lateral lobectomy for selected tumors.

Lim et al. [11] published the results of "conservative parotidectomy", defined as any procedure less extensive than a lateral lobectomy in which less than the full facial nerve was exposed. They presented a series of 43 patients with a parotid cancer limited to the lateral lobe. Sixteen $(37 \%)$ were high-grade and $27(63 \%)$ were low-grade cancers. Surgical treatment was followed by radiotherapy for 10 patients. Radiotherapy was indicated when there was the presence of multiple metastases, extracapsular spread, metastases found on histopathological evaluation, or if histopathological evaluation of the resected primary tumor demonstrated a positive margin. Local recurrence developed in four cases. The overall survival rate and the disease-free rate at five years were $88 \%$ and $79 \%$. The authors concluded that conservative parotidectomy with appropriate postoperative radiotherapy may be an acceptable procedure for the treatment of low-grade parotid cancers confined to the lateral lobe, when the facial nerve is sufficiently distant from the tumor.

Cockerill et al. [16] reported a large pediatric series of malignant salivary gland tumors, with 49 malignancies originating in the parotid gland. Most were low-grade tumors. The most frequent surgical approach was total parotidectomy $(65 \%)$, but a number were treated with enucleation (22\%) and the remainder with lateral lobectomy $(10 \%)$. The extent of the surgery correlated with loco-regional control, particularly within the enucleation group, as $64 \%$ of these patients had a recurrence. The recurrence rate after lateral and total parotidectomy was $(40 \%)$ and $(16 \%)$. The only statistically significant difference in tumor control was between enucleation and total parotidectomy. Therefore, the authors recommend total parotidectomy for tumors with deep-lobe location, high grade, positive intraparotid lymph nodes or positive cervical lymph nodes. The enucleation of parotid tumors was strongly discouraged by these authors.

Stodulski et al. [17] analyzed a group of 32 patients, with malignant tumors treated mainly with surgery with negative $(>1 \mathrm{~mm})$ but close $(<5 \mathrm{~mm})$ surgical margins, and who did not receive post-operative radiation. Only two cases were treated with PLL, one T1 and one T2. Neither of those two cases had recurrence. According to the authors, the watch and wait strategy with intensive follow-up seemed justified in cases of close margins after the excision of small low-grade parotid tumors.

The same group (Mantsopoulos et al.) published three papers on this subject $[12,18,19]$. The most recent [19] was an extension of the two prior papers, with the addition of several new cases. They reported on 14 patients with a low-grade malignancy treated by ECD and no further surgery or radiotherapy. All cases were stages pT1-2 pN0. With a mean follow-up of 3.1 years, all patients remained tumor-free. If the tumor was adequately resected by the primary surgery (R0), the authors felt that ECD was oncologically sufficient for carefully selected cases. These included completely removed T1 to T2 low-grade carcinomas (acinic cell carcinoma polymorphous low-grade carcinoma, low-grade mucoepidermoid carcinoma) and compliant patients for regular follow-up. In their opinion, ECD alone for these carefully selected tumors did not seem to be associated with a negative oncologic and functional outcome.

In conclusion, the published data comprises 107 cases, i.e., 46PLL, 50 ECDs and 11 enucleations. Only Lim et al. [11] performed PLL for suspected malignant tumors. The other surgeons performed limited surgery for suspected benign tumors. The global local control was $91 \%$ for PLL, $88 \%$ for ECD and $36 \%$ for enucleation. 


\section{Discussion}

The object of this review was to analyze the role of limited surgery in the treatment of primary malignant parotid tumors. Eight of the nine studies [11-15,17-19] supported a limited approach in carefully selected cases. All were retrospective studies, with a small patient series, and most used limited resections for small, mobile, clinically benign, but pathologic low-grade cancers of the superficial lobe. Most authors used these limited surgeries (PLL or ECD) in the setting of a suspected benign lesion and almost $30 \%$ of those patients were treated with post-operative radiotherapy. The advantage of the "less-than-superficial parotidectomy" approach is that the risk of facial nerve paralysis may be reduced, hopefully without compromising oncologic results. Three studies used PLL (Lim et al. defined it as conservative parotidectomy) and the remaining four used ECD for selected cases of presumed benign tumors.

Primary parotid gland cancers comprise a heterogeneous group of histologic entities with varying tumor biology and metastatic behavior, ranging from slow growing, less aggressive, to highly aggressive [20]. This heterogeneity can account for the controversy around the extent of the surgery. The less aggressive low-grade tumors are the most controversial group. McGurk et al. (15) used the term simple, or later, "clinical low grade" [21], to refer to the less aggressive tumors. They consider the clinical grade as the most important factor in tumor classification.

The study showing a negative result for limited surgery was in a pediatric subgroup treated with enucleation [16]. This enucleation group had a higher rate of local recurrence, and the authors strongly discouraged this approach. Enucleation is not an acceptable option for even benign tumors. Enucleation and extracapsular dissection and different surgical techniques can often be very hard to distinguish by reviewing published papers.

Only one study addressed the management of a suspected malignant tumor [11], with acceptable local control (90.5\%) and post-operative radiotherapy used in $22 \%$ of the cases. When a presumably benign tumor is treated with PLL or ECD and then is found to be a low-grade malignancy, published data [12-14,17-19] suggest that in highly selected cases, limited resections can be effective. The typical management is to complete the surgery one would have done if the actual pathology and tumor extent and behavior were known prior to the first operation. This will best reduce the risk of loco-regional recurrence [22-30]. However, the studies analyzed here suggest that, for select low-grade, R0, clinically N0, with no risk factors (Table 2), an observation approach may be a valid option.

Table 2. Proposed indications for malignant parotid tumours, considering two situations: suspected malign tumour or presumably benign. This is a general guideline; each case needs an individual decision with open discussion with the patient.

\begin{tabular}{|c|c|c|c|}
\hline Table & & & Extension of Parotidectomy \\
\hline \multirow{3}{*}{$\begin{array}{l}\text { Suspected malign } \\
\text { tumour }\end{array}$} & \multirow[t]{2}{*}{$\begin{array}{c}\text { Stage I-II } \\
\text { (T1-2N0M0) }\end{array}$} & $\begin{array}{l}\text { Low grade (and } \\
\text { superficial) }\end{array}$ & $\begin{array}{l}\text { Lateral parotidectomy } \\
\text { (Less than lateral parotidectomy in very } \\
\text { selected cases can be considered, } \\
\text { but more prospective data are needed } \\
\text { to generalise this indication) }\end{array}$ \\
\hline & & $\begin{array}{l}\text { High grade or } \\
\text { intermediate grade or } \\
\text { any grade in deep lobe }\end{array}$ & Total parotidectomy \\
\hline & \multicolumn{2}{|c|}{ Stage III-IV } & Total parotidectomy \\
\hline \multirow{3}{*}{$\begin{array}{l}\text { Presumably, benign } \\
\text { tumour but definitive } \\
\text { histology reveals } \\
\text { malignancy }\end{array}$} & \multirow{2}{*}{ Stage I-II (pT1-2 N0M0) } & $\begin{array}{c}\text { Free margins, superficial, } \\
\text { low grade }\end{array}$ & Close follow-up \\
\hline & & $\begin{array}{l}\text { Margins affected, more } \\
\text { than low grade }\end{array}$ & Complete a total parotidectomy \\
\hline & \multicolumn{2}{|c|}{ Stage III-IV } & Complete a total parotidectomy $* *$ \\
\hline
\end{tabular}

* This situation must be minimized using complete preoperative studies. ${ }^{* *}$ Individualize in relation of the prognostic factors and the need of radiotherapy +- chemotherapy). 
There is great value in assuring negative margins, as loco-regional control remains an important factor in long-term oncologic success. Achieving a negative surgical margin is one of the few prognostic factors in salivary gland malignancies that is controlled by the surgeon [24]. Unfortunately, the margin status is not always reported in clinic-pathological studies of salivary gland tumors.

Mantsopoulos et al. $[18,19]$ reported on 25 patients where revision parotidectomy was performed after ECD. Further tumor cells were detected in the histology specimens in only three cases. One of these three cases had a low-grade tumor. Controversy as to the extent of the resection occurs mainly for low grade tumors. The amount of gland resected depends on the tumor type, location, and involvement of intraparotid and regional nodes.

As surgery for benign parotid tumors has evolved to include more conservative resections [31-34], there will be more cases of presumably benign tumors that are later found to be malignant. Furthermore, the incidence of malignant parotid tumors seems to have increased in recent years [35], especially T1 and T2 tumors. Table 2 gives a general guideline for treatment of these patients, but each case needs individual decision-making, including an open discussion with the patient. Low-grade tumors generally include low grade mucoepidermoid carcinoma, acinic cell adenocarcinoma, epithelial-myoepithelial carcinoma, polymorphous low-grade adenocarcinoma, hyalinizing clear cell carcinoma, basal cell adenocarcinoma, sebaceous adenocarcinoma, sebaceous lymphadenocarcinoma, mucinous adenocarcinoma, papillary cystoadenocarcinoma, myoepithelial carcinoma, oncocytic carcinoma, and hyalinizing clear cell carcinoma. We usually recommend a lateral lobectomy as the standard procedure for these early low-grade malignant parotid tumors, if there is no involvement of the parotid and regional nodes and the tumor can be widely excised. We recognize that a partial parotidectomy can also be done for very select low-grade small peripheral favorably behaving tumors. It is important to assure adequate follow-up for these patients. More cases are needed to confidently recommend this paradigm shift in management.

Finally, one should try to reduce the occurrence of unexpected malignancy found on permanent pathology. Published data show an incidence of this between 3\% and 5\%. McGurk et al. [15] demonstrated that 32 of 662 clinically "benign" cases $(4.8 \%)$ were subsequently found to have malignant histology, with two-thirds of them being low-grade carcinomas. Mantsopoulos et al. [18,19] found this situation in 30 out of 878 (3.4\%) cases, with low-grade malignancies in 22 out of 30 $(73.3 \%)$ cases.

The ideal preoperative work-up for a presumably benign parotid tumor may reduce this rate by careful attention to history and tumor behaviour, performing an FNA, and having readily available frozen section pathology for intraoperative decision making. Many authors [3,5-7,9,36,37] are in favor of a complete preoperative study with fine needle aspiration cytology (FNAC). Some authors $[38,39]$ support the role of core needle biopsy (CNB) in the preoperative diagnosis of parotid neoplasms.

An accurate preoperative work-up and intraoperative frozen section pathology should result in optimal surgical planning and counselling of the patient. This would avoid the emotional and psychological distress caused for patients having to consider a second surgery.

\section{Conclusions}

Based on the current literature, there is little evidence to recommend less than a comprehensive lateral parotid lobectomy for known low-grade primary malignant parotid tumors.

If a partial lobectomy has been performed for a presumably benign tumor that proves to be a low-grade malignancy; then, if the tumor is stage T1, with free margins, close follow-up may be recommended. Considering the potential additional morbidity of future recurrence, it is important to improve preoperative diagnosis and intraoperative diagnosis for optimal surgical management.

Author Contributions: Conceptualization, M.Q., K.D.O., K.S., M.H. and A.F.; methodology, M.Q., J.G.L.; writing-original draft preparation, M.Q. and A.F.; writing-review and editing, all coauthors; All authors have read and agreed to the published version of the manuscript.

Funding: This research received no external funding. 
Conflicts of Interest: The authors declare no conflict of interest.

\section{References}

1. Spiro, I.J.; Wang, C.C.; Montgomery, W.W. Carcinoma of the parotid gland. Analysis of treatment results and patterns of failure after combined surgery and radiation therapy. Cancer 1993, 71, 2699-2705. [CrossRef]

2. Stennert, E.; Kisner, D.; Jungehuelsing, M.; Guntinas-Lichius, O.; Schröder, U.; Eckel, H.E.; Klussmann, J.P. High incidence of lymph node metastasis in major salivary gland cancer. Arch. Otolaryngol. Head Neck Surg. 2003, 129, 720-723. [CrossRef] [PubMed]

3. Boahene, D.K.; Olsen, K.D.; Lewis, J.E.; Pinheiro, A.D.; Pankratz, V.S.; Bagniewski, S.M. Mucoepidermoid carcinoma of the parotid gland: The Mayo clinic experience. Arch. Otolaryngol. Head Neck Surg. 2004, 130, 849-856. [CrossRef] [PubMed]

4. Vander Poorten, V.L.; Balm, A.J.; Hilgers, F.J.; Tan, I.B.; Loftus-Coll, B.M.; Keus, R.B.; van Leeuwen, F.E.; Hart, A.A. The development of a prognostic score for patients with parotid carcinoma. Cancer 1999, 85, 2057-2067. [CrossRef]

5. Cracchiolo, J.R.; Shaha, A.R. Parotidectomy for parotid cancer. Otolaryngol. Clin. N. Am. 2016, 49, 415-424. [CrossRef] [PubMed]

6. Lewis, A.G.; Tong, T.; Maghami, E. Diagnosis and management of malignant salivary gland tumors of the parotid gland. Otolaryngol. Clin. N. Am. 2016, 49, 343-380. [CrossRef]

7. Lombardi, D.; Mcgurk, M.; vander Poorten, V.; Guzzo, M.; Accorona, R.; Rampinelli, V.; Nicolai, P. Surgical treatment of salivary malignant tumors. Oral Oncol. 2017, 65, 102-113. [CrossRef]

8. Olsen, K.D.; Quer, M.; de Bree, R.; van der Poorten, V.; Rinaldo, A.; Ferlito, A. Deep lobe parotidectomy-why, when, and how? Eur. Arch. Otorhinolaryngol. 2017, 274, 4073-4078. [CrossRef]

9. Thielker, J.; Grosheva, M.; Ihrler, S.; Wittig, A.; Guntinas-Lichius, O. Contemporary Management of Benign and Malignant Parotid Tumors. Front. Surg. 2018, 5, 39. [CrossRef]

10. Carlson, E.R.; Schlieve, T. Salivary Gland Malignancies. Oral Maxillofac. Surg. Clin. N. Am. 2019, 31, $125-144$. [CrossRef]

11. Lim, Y.C.; Lee, S.Y.; Kim, K.; Lee, J.S.; Koo, B.S.; Shin, H.A.; Choi, E.C. Conservative parotidectomy for the treatment of parotid cancer. Oral Oncol. 2005, 41, 1021-1027. [CrossRef] [PubMed]

12. Mantsopoulos, K.; Koch, M.; Iro, H. Extracapsular dissection as sole therapy for small low-grade malignant tumors of the parotid gland. Laryngoscope 2017, 127, 1804-1807. [CrossRef] [PubMed]

13. Renehan, A.G.; Gleave, E.N.; Slevin, N.J.; McGurk, M. Clinico-pathological and treatment-related factors influencing survival in parotid cancer. Br. J. Cancer 1999, 80, 1296-1300. [CrossRef] [PubMed]

14. Witt, R.L. Facial nerve function after partial superficial parotidectomy: An 11-year review (1987-1997). Otolaryngol. Head Neck Surg. 1999, 121, 210-213. [CrossRef]

15. McGurk, M.; Thomas, B.L.; Renehan, A.G. Extracapsular dissection for clinically benign parotid lumps: Reduced morbidity without oncological compromise. Br. J. Cancer 2003, 89, 1610-1613. [CrossRef]

16. Cockerill, C.C.; Gross, B.D.; Contag, S.; Rein, S.; Moore, E.J.; Olsen, K.D.; Orvidas, L.J. Pediatric malignant salivary gland tumors: 60 year follow up. Int. J. Pediatr. Otorhinolaryngol. 2016, 88, 1-6. [CrossRef]

17. Stodulski, D.; Mikaszewski, B.; Majewska, H.; Wiśniewski, P.; Stankiewicz, C. Close surgical margin after conservative parotidectomy in early stage low-/intermediate grade parotid carcinoma: Outcome of watch and wait policy. Oral Oncol. 2017, 68, 1-4. [CrossRef]

18. Mantsopoulos, K.; Mueller, S.; Goncalves, M.; Koch, M.; Iro, H. Completion surgery after extracapsular dissection of low-grade parotid gland malignant tumors. Head Neck 2019, 41, 3383-3388. [CrossRef]

19. Mantsopoulos, K.; Velegrakis, S.; Iro, H. Unexpected detection of parotid gland malignancy during primary extracapsular dissection. Otolaryngol. Head Neck Surg. 2015, 152, 1042-1047. [CrossRef]

20. El-Naggar, A.K.; Chan, J.K.C.; Grandis, J.R.; Takata, T.; Slootweg, P.J. (Eds.) WHO Classification of Head and Neck Tumors, 4th ed.; International Agency for Research on Cancer: Lyon, France, 2017.

21. Mamelle, G. Total versus partial parotidectomy. In Controversies in the Management of Salivary Glands Disease; McGurk, M., Combes, J., Eds.; Oxford University Press: Oxford, UK, 2013; pp. 194-202.

22. Theriault, C.; Fitzpatrick, P.J. Malignant Parotid Tumors Prognostic Factors and Optimum Treatment. Am. J. Clin. Oncol. 1986, 9, 510-516. [CrossRef] 
23. Vartanian, J.G.; Gonçalves Filho, J.; Kowalski, L.P.; Shah, J.P.; Suárez, C.; Rinaldo, A.; De Bree, R.; Rodrigo, J.P.; Hamoir, M.; Takes, R.P.; et al. An evidence-based analysis of the management of N0 neck in patients with cancer of the parotid gland. Expert Rev. Anticancer Ther. 2019, 19, 899-908. [CrossRef]

24. Terhaard, C.H.; Lubsen, H.; Van der Tweel, I.; Hilgers, F.J.; Eijkenboom, W.M.; Marres, H.A.; Tjho-Heslinga, R.E.; de Jong, J.M.; Roodenburg, J.L.; Dutch Head and Neck Oncology Cooperative Group. Salivary gland carcinoma: Independent prognostic factors for locoregional control, distant metastases, and overall survival: Results of the Dutch head and neck oncology cooperative group. Head Neck 2004, 26, 681-692. [CrossRef]

25. McKean, M.E.; Lee, K.; McGregor, I.A. The distribution of lymph nodes in and around the parotid gland: An anatomical study. Br. J. Plast. Surg. 1985, 38, 1-5. [CrossRef]

26. Pisani, P.; Ramponi, A.; Pia, F. The deep parotid lymph nodes: An anatomical and oncological study. J. Laryngol. Otol. 1996, 110, 148-150. [CrossRef] [PubMed]

27. Garatea-Crelgo, J.; Gay-Escoda, C.; Bermejo, B.; Buenechea-Imaz, R. Morphological study of the parotid lymph nodes. J. Craniomaxillofac. Surg. 1993, 21, 207-209. [CrossRef]

28. Klussmann, J.P.; Ponert, T.; Mueller, R.P.; Dienes, H.P.; Guntinas-Lichius, O. Patterns of lymph node spread and its influence on outcome in resectable parotid cancer. Eur. J. Surg. Oncol. 2008, 34, 932-937. [CrossRef] [PubMed]

29. Olsen, K.D.; Moore, E.J. Deep lobe parotidectomy: Clinical rationale in the management of primary and metastatic cancer. Eur. Arch. Otorhinolaryngol. 2014, 271, 1181-1185. [CrossRef]

30. Nisa, L.; Salmina, C.; Dettmer, M.S.; Arnold, A.; Aebersold, D.M.; Borner, U.; Giger, R. Implications of intraglandular lymph node metastases in primary carcinomas of the parotid gland. Laryngoscope 2015, 125, 2099-2106. [CrossRef]

31. Mantsopoulos, K.; Koch, M.; Klintworth, N.; Zenk, J.; Iro, H. Evolution and changing trends in surgery for benign parotid tumors. Laryngoscope 2015, 125, 122-127. [CrossRef]

32. Quer, M.; Guntinas-Lichius, O.; Marchal, F.; Vander Poorten, V.; Chevalier, D.; León, X.; Eisele, D.; Dulguerov, P. Classification of parotidectomies: A proposal of the European Salivary Gland Society. Eur. Arch. Otorhinolaryngol. 2016, 273, 3307-3312. [CrossRef]

33. Witt, R.L. Extracapsular dissection with facial nerve dissection for benign parotid tumors. Otolaryngol. Head Neck Surg. 2016, 154, 572-574. [CrossRef]

34. Quer, M.; Vander Poorten, V.; Takes, R.P.; Silver, C.E.; Boedeker, C.R.; de Bree, R.; Rinaldo, A.; Sanabria, A.; Shaha, A.R.; Pujol, A.; et al. Surgical options in benign parotid tumors: A proposal for classification. Eur. Arch. Otorhinolaryngol. 2017, 274, 3825-3836. [CrossRef] [PubMed]

35. Del Signore, A.G.; Megwalu, U.C. The rising incidence of major salivary gland cancer in the United States. ENT Ear Nose Throat J. 2017, 96, E13-E16. [CrossRef] [PubMed]

36. Lin, A.C.; Bhattacharyya, N. The utility of fine needle aspiration in parotid malignancy. Otolaryngol. Head Neck Surg. 2007, 136, 793-798. [CrossRef] [PubMed]

37. Lundberg, M.; Munsterhjelm, B.; Mäkitie, A.; Leivo, I. Immunohistochemical Staining of Histological Fragments Derived from Salivary Gland Tumor Fine-Needle Biopsy Aspirates. Acta Cytol. 2017, 61, 17-20. [CrossRef]

38. Zbären, P.; Triantafyllou, A.; Devaney, K.O.; Vander Poorten, V.; Hellquist, H.; Rinaldo, A.; Ferlito, A. Preoperative diagnostic of parotid gland neoplasms: Fine-needle aspiration cytology or core needle biopsy? Eur. Arch. Otorhinolaryngol. 2018, 275, 2609-2613. [CrossRef]

39. Witt, B.L.; Schmidt, R.L. Ultrasound-guided core needle biopsy of salivary gland lesions: A systematic review and meta-analysis. Laryngoscope 2014, 124, 695-700. [CrossRef]

(C) 2020 by the authors. Licensee MDPI, Basel, Switzerland. This article is an open access article distributed under the terms and conditions of the Creative Commons Attribution (CC BY) license (http://creativecommons.org/licenses/by/4.0/). 